Cell Research(1995),5,235-242

\title{
Differential regulationof glutathione S-transferase Yb1 mRNA levels in rat prostate, liver and brain by andro- gen
}

\author{
ZHANG Yu A N , Yo u d u A N ZHANG, CH A w N S H A N G \\ CHANG* $^{*}$ YONGLIAN ZHANG ${ }^{1}$ \\ Shanghai Institute of Biochemistry, Academia Sinica, 320 \\ Yueyang Road, Shanghai 200031, China. \\ * Department of Human Oncology, University of Wiscon- \\ sin, 600 Highland Avenue, Madison, WI 53792, USA.
}

\begin{abstract}
Northern blot analysis of glutathione S-transferase (GST) Yb1 mRNA in different tissues of male and female rats revealed that its tissue-specific transcription patterns were highly sex hormone related. Although the GST Yb1 mRNA could be detected in most of the tissues examined at various levels, the highest abundance was observed in the ventral prostate, uterus and liver, which were the main target tissue for androgen, estrogen and glucocorticoid respectively. The effect of androgen on the transcription of GST Yb1 was also tissue-specific. Since androgen withdrawal by castration caused the up-regulation of GST Yb1 mRNA in the ventral prostate but down-regulation in the liver and no effect in the brain, evaluation of this system for studying the regulation mechanisms of gene expression by which androgen exerts its differential effects has been discussed.
\end{abstract}

Key words: GST Yb1 mRNA, androgen regulation, rat prostate, rat liver, rat brain.

\section{INTRODUCTION}

Androgen is essential for the development, growth and function of its target organs by controlling the expression of a limited number of specific genes in different

1. To whom reprint requests should be addressed 


\section{Androgen regulation of GST Yb1 mRNA in rat tissues}

directions and to different extents. Our work on rat prostatic steroid-binding protein (PSBP) genes has shown the androgen induction of these proteins to be a good model for the study of the mechanism of the positive modulation of gene transcription by this hormone[1-3]. However, not much is known about the mechanism of hormonal repression. To understand how the same androgen receptor can direct the expression of target genes in opposite ways, the search for a suitable model of negative control has become essential. In this respect, our previous studies with dot blot analysis which showed GST Yb1 subunit gene expression to be negatively regulated by androgen in the rat ventral prostate seemed promising[4-6].

The rat glutathione S-transferases (GSTs) are a family of isozymes which catalyze the nucleophilic attack of the thiol of glutathione on various electrophilic acceptors[7, 8]. In addition, the transferases bind a number of hydrophobic compounds such as heme, bilirubin and dexamethasone. Their expression can be induced by various xenobiotics such as transstilbene oxide[9, 10] and for many toxic xenobioties, glutathione S-conjugate formation represents a detoxication pathway[7, 8]. The GSTs are either homodimers or heterodimers composed of at least eight subunits (Ya, Yb1, $\mathrm{Yb} 2, \mathrm{Yb} 3, \mathrm{Yc}, \mathrm{Yk}, \mathrm{Yn}$ and $\mathrm{Yp}$ ) which are expressed tissue-specifically and can be distinguished according to their substrate specificity. The Yb1 subunit gene is one of the three cloned $\mathrm{Yb}$ cDNAs isolated and characterised. This paper reports our studies on the androgen effects on the tissue-specific expression of the GST Yb1 gene.

\section{MATERIALS AND METHODS}

\section{Animals}

Adult male and female Sprague-Dawley rats (250 - 300g) were bought from Shanghai Animal Center of Academia Sinica. For androgen withdrawal of the male rats by castration, male rats were anesthetized by the administration of $40-60 \mathrm{mg}$ of pentobarbital sodium per kilogram of body weight and castrated by the scrotal route. For androgen manipulation by Ethylene Dimethane Sulfonate (EDS) treatment, male rats received a single EDS injection (75mg EDS in DMSO/kg body weight). Animal experiments were carried out twice. Serum for testosterone determination by Kit and ventral prostate for RNA preparation were collected from the animals before and after EDS treatment at different time intervals. At least five rats were involved in each point.

\section{Reagents}

Guanidinium thiocyanate and sarkosyl were obtained from Sigma, $\alpha-{ }^{32} \mathrm{p}$ dATP $(3000 \mu \mathrm{Ci} / \mathrm{mmol})$ from Amersham.

\section{RNA extraction and northern blot analysis}

Total RNA were isolated from rat tissues by the single-step acid guanidinium thiocyanatephenol-chloroform extraction as described by Chomzynski and Sacchif[11]. The RNA preparations were qualified with A260/A280 = 1.8 - 1.9, with no DNA contamination as checked by DABA DNA assay[12] and of high integrity as judged by sharp bands for $28 \mathrm{~S}$ and $18 \mathrm{~S}$ rRNAs shown on the gel by ethidium bromide staining. So the concentration of each RNA sample can be determined directly by spectrophotometry. Equal amounts of total RNA were eletrophoresed on the $1.2 \%$ formaldehyde agarose gel[13]. The quality and the quantity of the loaded samples were rechecked by the integrity and the intensity of the $28 \mathrm{~S}$ and $18 \mathrm{~S}$ rRNA bands. Then, RNAs were transferred and fixed on the 
nylon membrane, hybridized with ${ }^{32}$ p-GST Yb1 cDNA, $\beta$-actin cDNA or GAPDH cDNA (labelled by random primer labelling Kit) overnight at $65{ }^{\circ} \mathrm{C}$ as described previously[14]. Autoradiography was carried out at $-80{ }^{\circ} \mathrm{C}$ and the intensity of the signals was measured by densitometric scanning with a C3-930 Shimadzu Dual-wavelength Scanner. For reprobing, the damp blots were washed at $95{ }^{\circ} \mathrm{C}$ for $20 \mathrm{~min}$ in $10 \mathrm{mM}$ Tris-HCl (pH 8.0), $1 \mathrm{mM}$ EDTA and 0.1\% (w/v) SDS to remove the previous signals and be ready for re-prehybridization. Northern blot analysis was repeated at least twice.

\section{RESULTS AND DISCUSSION}

GST Yb1 gene was highly expressed in the three main target tissues of steroid hormones (androgen, estrogen and glucocorticoid)

GST Yb1 mRNAs were investigated by Northern blot analysis of total RNA extracted from different rat tissues with ${ }^{32} \mathrm{p}$ labelled cDNA as a probe. The results are shown in Fig 1. Usually, the mRNA for $\beta$-actin was used as an internal control to normalize the tested mRNAs determination. Unfortunately, the steady state of $\beta$-actin mRNAs were varied greatly in the tissues tested and even with different size in some tissues as the case of heart, coagulating gland and seminal vesicle which were its cross-hybridizing signals for $\alpha$ - or $\gamma$-actin mRNAs[15]. When choosing another popular house-keeping gene GAPDH (Glyceraldehyde-3-phosphate- dehydrogenase) as internal control, the situation seemed to be not improved (Fig 1). As stated in the Materials and Methods, several reference parameters were provided to ensure the quality and quantity of the total RNA and the reproducibility of experiments. Additionally, our results of $\beta$-actin gene expression in different tissues agreed with those of other reports[15, 16], thus supporting the conviction that there were no problem with RNA loading variations.

The expression of the GSTs genes has been reported to be tissue-specific, e.g. subunit Ya and Yc are not expressed in heart and testis, Yp not in liver, Yb1 not in kidney[4, 20], while Yb3 is brain specific[21]. Our experiment amply illustrated this point. It is of interest to note that the highest level of expression was found in the chief target organs of three steroid hormones, i.e. ventral prostate (androgen), uterus (estrogen) and liver (glucocorticoid), followed by other classical androgen target tissues such as testis and coagulating gland. Of the tissues with only low levels of expression, brain ranks higher and spleen the lowest, while barely detectable in kidney. This result indicated strongly that the expression of GST Yb1 gene must be somehow influenced by these steroid hormones.

\section{Androgen regulation of GST Yb1 $\mathrm{mRNA}$ in rat ventral prostate, liver and brain}

As an active expression of the GST Yb1 gene was found in the androgen target tissues, the role of androgen in three tissues was investigated, the ventral prostste as one of the classical androgen target tissue; the liver as an important tissue concerned with detoxication and the brain a third tissue with an average level of expression. The results with the ventral prostate were in agreement with those by dot blot ana- 
(A)

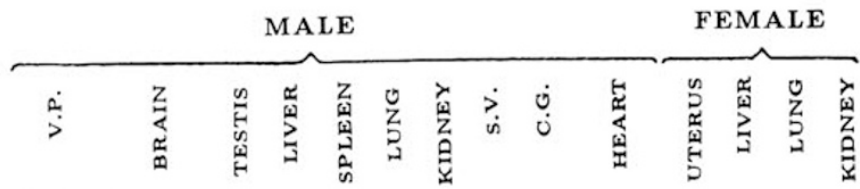
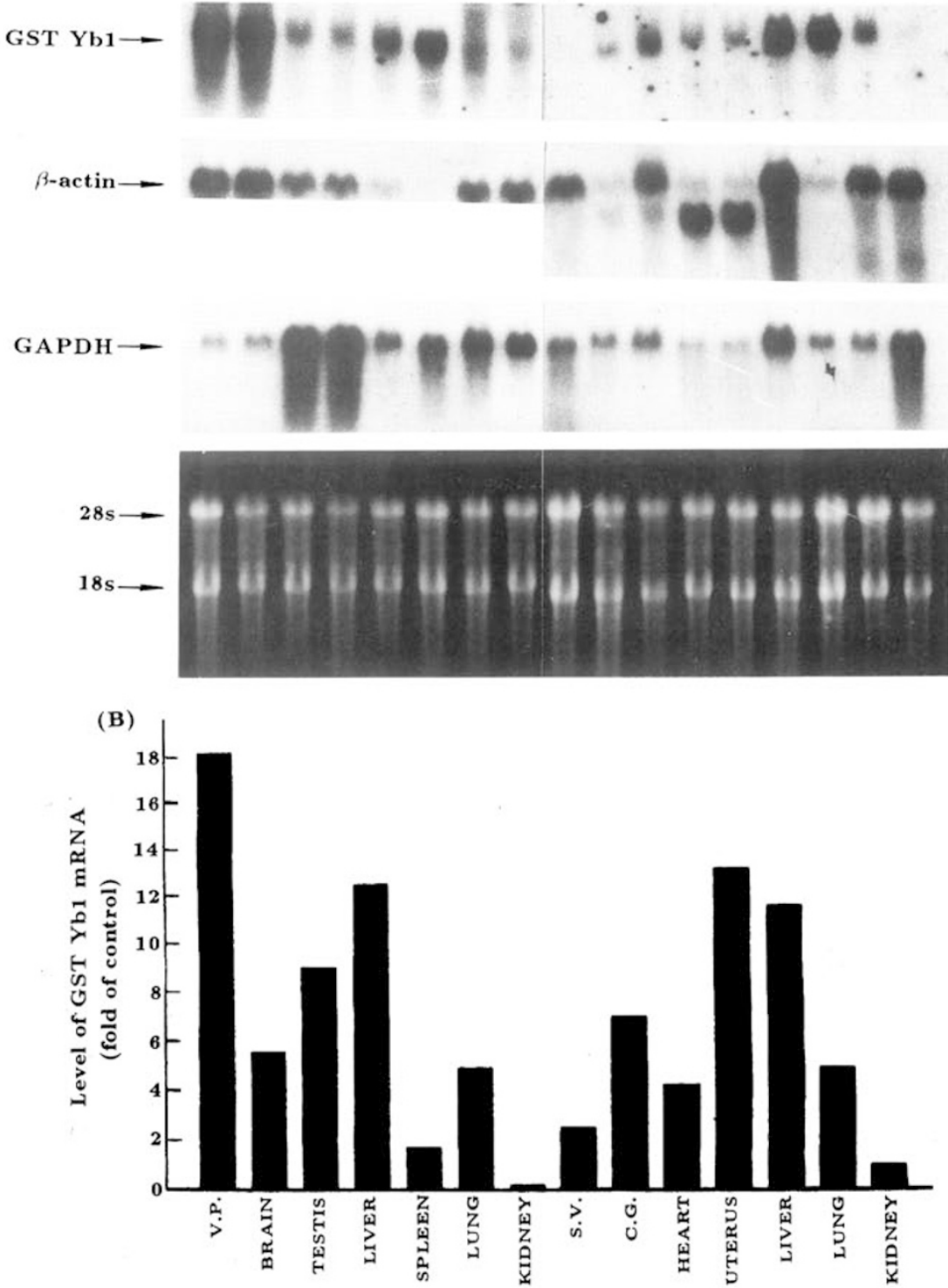

Fig 1. Tissue-specificity of GST Yb1 gene expression in the male and female rats.

(A) Northern blot analysis: $30 \mu \mathrm{g}$ of total RNA in each lane from different tissues were run on the $1.2 \%$ formaldehyde agarose gel, transferred to nylon membrane and hybridized with ${ }^{32} \mathrm{P}$ - labeled probes as indicated. Due to the limitation of the tank size, all RNA preparations were analyzed on two blots on which duplicate samples were loaded in parellel (lanes cut) to make the data from two blots comparable.

(B) Relative levels of GST Yb1 mRNA in different tissues were determined by densitometric scanning and indicated as black bars. The level in kidney of female rats was set to 1. V.P. ventral prostate; S. V. seminal vesicle; C.G. coagulating gland. 
lysis reported previously[4, 5, 17]. The GST Yb1 mRNA level increased after androgen withdrawal by castration and reached the highest level on day 3 postoperation, then gradually decreased until down to $50 \%$ of the normal by the 10th day as indicated in Fig 2. Two internal standards, the $\beta$-actin and GAPDH mRNAs were not affected by castration as expected. In order to get an overview of the regulation feature of GST Yb1 mRNA in the ventral prostate by androgen manipulation, EDS treatment of the animal was carried out to address this subject. It was well documented that EDS could specifically eliminate the Leydig cells in testis which were the main source of testosterone secretion. Moreover, the effects were gradually reversed two weeks after EDS administration[18, 19]. Fig 3 showed the correlation of the rat serum testosterone concentration with the GST Ybl mRNA in the ventral prostate after EDS treatment. The result from EDS treated animals strengthened the conclusion obtained by castration that the expression of GST Yb1 gene was down-regulated by androgen in ventral prostate.

Surprisingly, quite opposite results were observed with liver upon castration. Both the GST Yb1 gene and those internal standards, $\beta$-actin and GAPDH gene expressions showed a transient decrease as shown in Fig 4. It suggested that androgen withdrawl might give rise to a non-specific inhibition of gene transcription in liver. The brain, on the other hand, was not sensitive to such androgen manipulation as shown in Fig 5 .

(A)

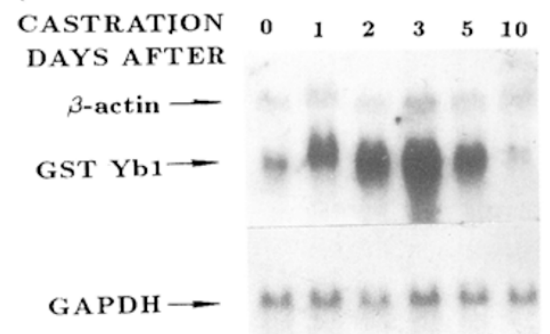

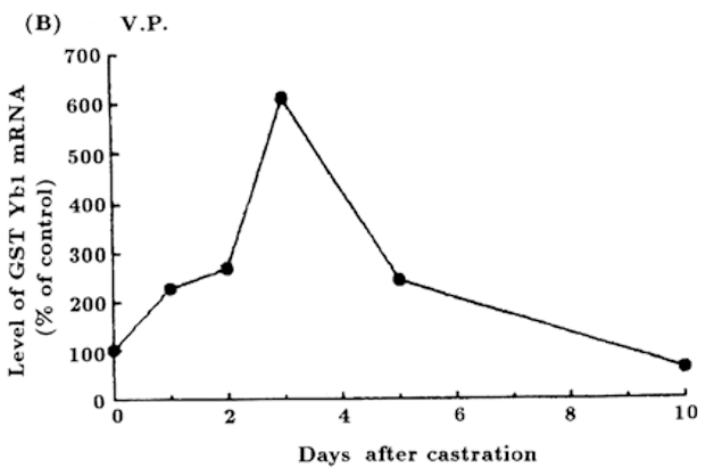

Fig 2. The effect of castration on the GST Yb1 mRNA in the rat ventral prostate.

(A) Northern blot analysis: $20 \mu \mathrm{g}$ of total RNA from normal and 1, 2, 3, 5 and 10 days post-castration rats were processed as described in Fig 1(A).

(B) Diagram for the changes of GST Yb1 mRNA in ventral prostate upon castration. The GST Yb1 mRNA levels (•) were determined by densitometric scanning and normalized with GAPDH mRNA. The level for normal rats (day 0) was set to 100. 

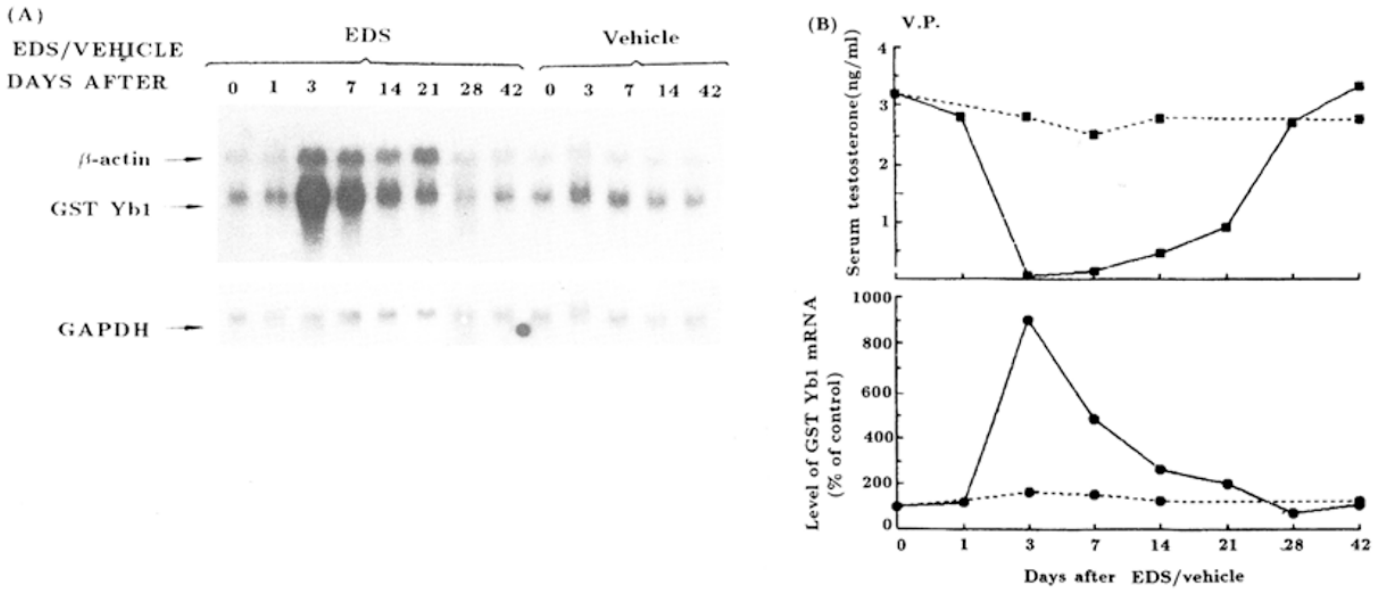

Fig 3. The effect of EDS treatment on the GST Yb1 mRNA in the rat ventral prostate.

(A) Northern blot analysis: $20 \mu \mathrm{g}$ of tatal RNA were loaded in each lane.

(B) Changes in levels of serum testosterone (घ) and GST Yb1 mRNA (•) in rats injected with $75 \mathrm{mg}$ EDS/Kg $(-)$ or DMSO-vehicle $(\longrightarrow$ The levels of GST Yb1 mRNA were normalized with those of GAPDH mRNA.

(A)

DAYS AFTER

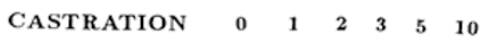

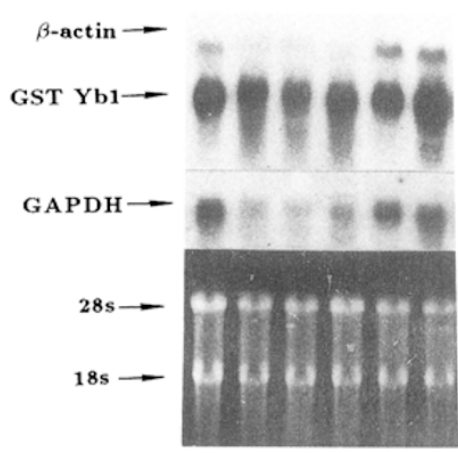

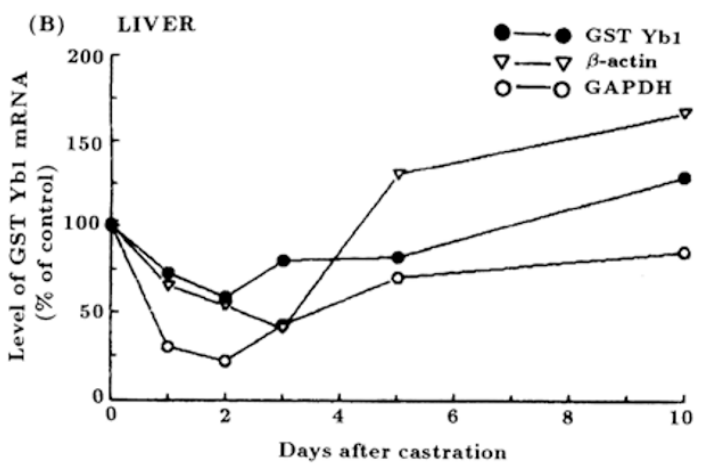

Days after castration

Fig 4. The effect of castration on the GST Yb1 mRNA in the rat liver.

(A) Northern blot analysis: $20 \mu \mathrm{g}$ of total RNA were run in each lane.

(B) Diagram for the changes of GST Yb1 mRNA in liver. 
The above experiments further suggested that the regulation of GST Yb1 gene was tissue-specific and occured in a diversified pattern. Since androgen withdrawal caused the up-regulation of GST Yb1 gene expression in ventral prostate but downregulation in liver and produced no effect in brain, this system would be a very interesting one for the study of different mechanisms by which androgen exerts its different effects. But the fact that only transient changes occured in the expression level upon androgen manipulation suggests that androgen evidently cannot be the unique factor involved. Therefore, this system is not a simple model of androgen regulation as the case of PSBP gene induction. However, as the interplay of steroid hormones with different tissue- specific transcription factors in the regulation of gene expression becomes elucidated more clearly, the GSTs gene model would still merit detailed study to improve our understanding of the complicated regulation of life processes.

(A)

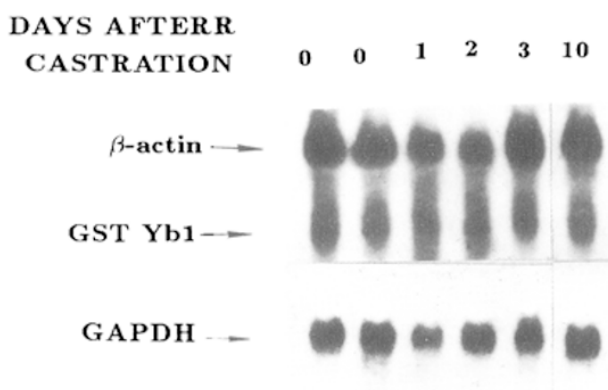

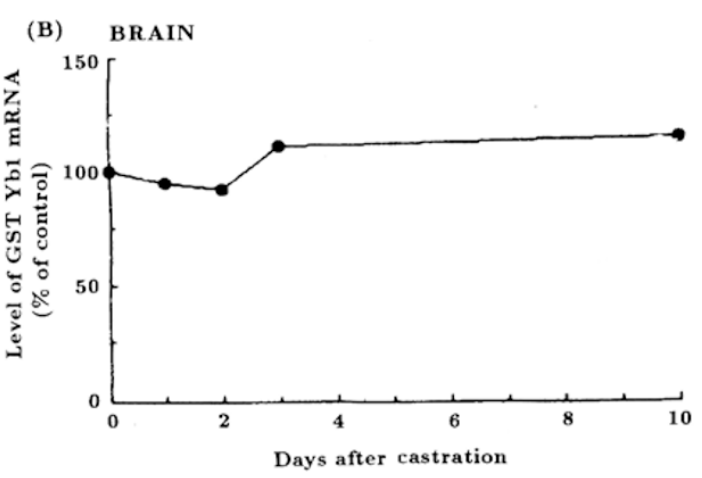

Fig 5. The effect of castration on the GST Yb1 mRNA in the rat brain.

(A) Northern blot analysis: 30 ug of total RNA were run in each lane.

(B) Diagram for the changes of GST Yb1 mRNA in brain upon castration. The levels of GST Yb1 mRNA were normalized with those of GAPDH mRNA.

\section{ACKNOWLEDGEMENTS}

This project was supported by grant from the Chinese Academy of Sciences. We are grateful to Dr. MG Parker in ICRF for providing $\beta$-actin cDNA clone, Dr. APN Themmen in Erasmus University for GAPDH cDNA clone. We would like to thank Mr. Ximeng ZUANG for making all the photos and Ms. Lianzheng LU and Mr. Xuegeng GU for the animal treatments.

\section{REFERENCES}

[1] Zhang YL, Parker MG. Regulation of rat prostatic steroid binding protein mRNAs by testosterone. Mol Cell Endocrinol 1985; 43:151-4. 


\section{Androgen regulation of GST Yb1 mRNA in rat tissues}

[2] Zhang YL, Zhou ZX, Zhang YD, Parker MG. Expression of androgen receptors and prostatic steroid binding protein during development of the rat ventral prostate J Endocrinol 1988; 117:361-6.

[3] Zhang YL, Parker MG, Bakker O. Tissue-specific differences in the binding of nuclear proteins to a CCAAT motif in the promoter of the androgen- regulated C3 gene. Mol Endocrinol 1990; 4:1219-25.

[4] Saltzman AG, Hiipakka RA, Chang C, Liao S. Androgen repression of the production of a 29-kilodalton protein and its mRNA in the rat ventral prostate. J Biol Chem 1987; 262:432-7.

[5] Chang C, Saltzman AG, Hiipakka RA, Huang IY, Liao S. Prostatic spermine- binding protein: cloning and nucleotide sequence of eDNA, amino acid sequence and androgen control of mRNA level. J Biol Chem 1987; 262:2826-31.

[6] Chang C, Saltzman AG, Sorensen NS, Hiipakka RA, Liao S. Identification of glutathione Stransferase $\mathrm{Yb} 1 \mathrm{mRNA}$ as the androgen-repressed mRNA by cDNA cloning and sequence analysis. Biol Chem 1987; 262:11901-3.

[7] Pickett CB, Lu AYH. Glutathione S- transferases: gene structure, regulation and biological function. Annu Rev Biochem 1989; 58:743-64.

[8] Mannervik B, Danielson UH. Glutathione transferases: structure and catalytic activity. CRC Crit Rev Biochem 1988; 23:281-334.

[9] Bhargava MM, Ohmi N, Listowsky I, Arias IM. Subunit composition, organic anion binding, catalytic and immunological properties of ligandin from rat testis. J Biol Chem 1980; 255:724-7.

[10] Homma H, Listowsky I Identification of Yb-glutathione-S-transferase as a major rat liver protein labelled with dexamethasone 21-methanesulfonate. Proc Natl Acad Sci USA 1985; 82:7165-9.

[11] Chomezynski P, Sacchi N. Single- step method of RNA isolation by acid guanidinium thiocyanatephenol -chloroform extraction. Anal Biol 1987; 162:156-9.

[12] Thomas PS, Farquhar MN. Specific Measurement of DNA in Nuclei and Nucleic Acids Using Diaminobenzoic Acid. Anal Biol 1978; 89:35-44.

[13] Rosen KM, Lamperti ED, Villa-Komaroff L. Optimizing the Northern blot procedure. BioTeehniques 1990; 8:398-403.

[14]Zhou ZX, Zhang YL, Zhang YD. The expression of the primary transcripts from prostatic steroid binding protein gene $\mathrm{C} 1$ and $\mathrm{C} 3$ of the rat ventral prostate during development. Chinese Acta Biochemica et Biophysica Sinica 1990; 22:461-8.

[15] Shani M, Nudel U, Zevin-Sonkin D, Zakut R, Givel D et al. Skeletal muscle actin mRNA: charecterization of the 3' untranslated region. Nucleic Acids Res 1981; 9:579-89.

[16] Ginzburg I, Baetselier A, Walker MD et al. Brain tubulin and actin cDNA sequences: isolation of recombinant plasmids. Nucleic Acids Res 1980; 8:3553-64.

[17]Briehl MM, Miesfield RL. Isolation and characterization of transcripts induced by androgen withdrawl and apoptotic cell death in the rat ventral prostate. Mol Endocrinol 1991; 5:1381-8.

[18] Morris ID, Phillips DM, Bardin CW. Ethylene dimethanesulfonate destroys Leydig cells in the rat testis. Endocrinol 1981; 118:709-19.

[19] Jackson AE, O'Leary PC, Ayers MM, Kretser DM. The effects of ethylene dimethane sulphonate (EDS) on rat Leydig cells: evidence to support a connective tissue origin of Leydig cells. Biol Reprod 1986; 35:425-37.

[20] Hayes JD. Purification and characterization of glutathione S- transferases P, S and N: Isolation from rat liver of $\mathrm{Yb} 1 \mathrm{Yn}$ protein, the existence of which was predicted by subunit hybridization in vitro. Biochem J 1984; 224:839-52.

[21]Abramovitz M, Listowsky I. Selective expression of a unique glutathione S-transferase Yb3 gene in rat brain. J Biol Chem 1987; 262:7770-3.

Received 17-8-1995. Revised 17-11-1995. Accepted 4-12-1995 